\title{
P83 - Asthma inflammatory subtype specific treatment; a randomised clinical study
}

\author{
Doaa Youssef*, Rabab Elbhedy, Hosam Salah \\ From 3rd Pediatric Allergy and Asthma Meeting (PAAM) \\ Athens, Greece. 17-19 October 2013
}

\section{Introduction}

Macrolides antibiotics, such as clarithromycine express immunomodulatory and tissue reparative effects that are distinct from their anti-infective properties, and have in vitro efficacy against neutrophils.

\section{Aim of study}

To determine the efficacy of add-on therapies that target eosinophilic and noneosinophilic airway inflammation and their effects on asthma control test, pulmonary function and asthma symptoms.

\section{Methods}

single blind randomized clinical trial; asthmatic children with persistent symptoms undergoing treatment with fluticasone $100 \mathrm{mg}$ bid and $\beta 2$ agonist as required were studied. Group A (23 males / 17 females, aged $11.5 \pm 1.8$ years) received fluticasone $200 \mathrm{mg}$ bid, and group B ( 21 males / 19 females, aged $11.5 \pm 1.8$ years) clarithromycine $15 \mathrm{mg} / \mathrm{kg}$ bid, in addition to fluticasone $100 \mathrm{mg}$ bid for 8 weeks. (FEV1\%, C-CAT, SABA use, sputum induced $\%$ of eosinophils and neutrophils) were compared before and after treatment in each group.

\section{Results}

In group A there is significant reduction of eosinophils percentage after treatment, and non significant increase in neutrophils percentage. There was significant improvement in FEV1\% predicted. While in group B there was non significant decrease in eosinophils, and significant decrease in neutrophils. In group A there was significant negative correlation between changes in FEV1\% and change in eosinophils and week positive correlation between changes in FEV1\% and changes in neutrophils. In group B there was significant positive

\footnotetext{
Zagazig University, Zagazig, Egypt
} 